\title{
Evaluation of the activity of a plant extract against Plasmopara viticola in grapes
}

\author{
Cristina Sudiro ${ }^{1,}$, Gregory Saccozza ${ }^{1}$, Federico Guglielmi ${ }^{1}$, Marie Hochart $^{1}$, Damiano Giacomello ${ }^{1}$, and Adriano \\ Altissimo $^{1}$ \\ ${ }^{1}$ LANDLAB srl, Via Quintarello 12/A, 36050 Quinto Vicentino -VI - Italy
}

\begin{abstract}
Downy mildew, caused by Plasmopara viticola in grapevine, is one of the most devastating and widespread fungal disease on causing serious harm to grape production. The heavy use of chemical pesticides, necessary to control the pests and pathogens, has caused issues with the resistance, resurgence and residues in food, as well as creating diffuse environmental pollution. In the last decade, biological control started to offer an alternative safe(r) and effective method to control diseases. In this paper, we investigate the potential activity of a plant extract to protect grapevine from downy mildew when used in strategy with a reduced dosage of the conventional fungicides (PPP). Four strategies were tested, with two of them giving the best results. Indeed, the use of LL017 increased the tolerance of the vine against $P$. viticola compared to its control with the same dosage of PPP, and with an efficacy closer to the full dosage of the PPP. In the tests where the yield was evaluated, the treatment with LL017 always resulted in a higher yield than the respective control with the same dosage of PPP and, in some cases, it gave a higher yield than even the positive control.
\end{abstract}

\section{Introduction}

Grapevine is one of the most important economic crops. However, a plethora of pathogenic microorganisms can cause diseases that affect, apart from the yield, the grapes organoleptic properties (as berries sugar content). This may result in a poor quality and potential great economic losses for the wine producers. Grapevine downy mildew, caused by Plasmopara viticola, is one of the most severe grapevine diseases. The majority of the varieties of $V$. vinifera are highly susceptible to $P$. viticola, thus, in order to controlling it, it requires regular and numerous fungicide applications. In fact, depending on the weather conditions (temperature, rain and humidity), the $\mathrm{N}^{\circ}$ of applications with either contact, translaminar or systemic fungicides can go up to 10-12 per cycle, with 7 to 10 days interval in the most affected regions [1].

Most of the most widely used fungicides contain copper, which may lead to soil and groundwater pollution [2]. Synthetic fungicides, instead, with single molecules as active ingredients, as metalaxyl [3, 4] and azoxystrobin [5], started to give rise to the development of resistant strains of $P$. viticola [6]. Moreover, overuse and/or misuse of synthetic pesticides often results in negative effects on humans and the environment, and toxicity to non-target organisms, with a huge impact on biodiversity [7].

In the last decade, biological control of plant pathogens has emerged as a promising alternative to synthetic pesticides and fungicides. Indeed, they are environmentally safe, safe for people and animals, and decrease the development rate of resistant strains [8]. Among biocontrol products, extracts of plants are widely studied. Interestingly, in fact, extracts of certain plants contain alkaloids, tannins, quinones, coumarins, phenolic compounds, essential oils and phytoalexins, which are known for their antifungal activity [9].

Considering grapevine protection, extracts from neem oil [10], Vitis canes [11], and Inula viscosa [12] exhibited a direct activity against $P$. viticola. Apart from a direct effect against the pathogen, plants extracts can also contain other compounds that can act as elicitors, and are therefore able to activate plants defense mechanisms [13].

The aim of this study was to evaluate the efficacy of a novel plant extract (LL017), aimed to improve grapevine resistance against downy mildew. In this work we evaluated the efficacy of 4 strategies, where LL017 was used in combination with different fungicides against $P$. viticola.

\section{Materials and methods}

\subsection{Set-up of the trials}

In 2019, two trials on wine grape cv. Merlot were performed, one in Cuneo area (2019 - C) and another in Vicenza (2019 - V). In 2020, a trial was performed in Vicenza in the same plots as $2019(2020$ - V). The distance between vines was $2,50 \times 0,8 \mathrm{~m}$. In order to avoid product drift from one plot to another, each plot was separated from its neighbour by an untreated plant.

\footnotetext{
*Corresponding author: c.sudiro@landlab.net
} 
Each plot consisted of 10 plants. Four replications per entry were used.

\subsection{Treatments application}

In each trial, there was a Negative control (CTR -) that was treated only with water, a Positive control $(\mathrm{CTR}+)$ that was treated with the full dosage of the conventional fungicide (PPP), the Control of the Strategy (CTR St), that was treated with a reduced dosage of the PPP, and the entry treated with the reduced dosage of the PPP with the addition of LL017 (St). Four strategies were used:

Strategy A (StA) - 9 applications: 3 treatments with 75\% PPP, 3 treatments with 50\% PPP (+ LL017), 3 treatments with $75 \% \mathrm{PPP}$ - total reduction: $33 \% \mathrm{PPP}$.

Strategy B (StB) - Application of 70\% PPP + LL017 at every treatment - total reduction: $30 \%$ PPP.

Strategy C (StC) - Alternate applications of LL017 and full dosage of PPP (blocks of 1-2 applications each) - total reduction: 50\% PPP.

Strategy D (StD) - Alternate applications of treatments with 65\% PPP + LL017 e treatments with $85 \%$ PPP (blocks of 1-2 applications each) - total reduction: $30 \% \mathrm{PPP}$.

In the trial $2019-\mathrm{C}$, the StA was used (Table 1), in the trial $2019-\mathrm{V}, \mathrm{StB}$ and StC were used (Table 2), In the trial 2020 - V StB and StD were used (Table 3). In the same tables, the dates for each treatment are reported.

\subsection{Efficacy assessment}

In order to evaluate the performance of the different strategies, the incidence and severity of downy mildew was assessed regularly from the start of the first symptoms. From each plant in the plot, 10 leaves and 10 bunches were picked randomly and the percentage of affected organs (disease incidence) and the percentage of organs' surface showing disease symptoms (disease severity) were estimated.

The efficiency of the strategies was calculated using Abbott's formula [14]:

$$
\% \text { effectiveness }=[(\mathrm{Ic}-\mathrm{It}) / \mathrm{Ic}] \times 100
$$

where Ic is the disease incidence or severity of the negative control, It is the disease incidence or severity of the treatment.

\subsection{Assessment of the yield}

For trials $2019-\mathrm{V}$ and $2020-\mathrm{V}$, the yield was assessed by harvesting and weighting the bunches from each plot. Bunches that were not suitable for vinification were removed and not weighted.

\subsection{Statistical analysis}

The statistical analysis (software Statistica by StatSoft) was performed by means of one-way analysis of variance (one-way ANOVA) with Duncan Test $(\alpha)=$ 0,05 . For each trait, at least one letter in common indicates no significant difference according to the Duncan test.

Table 1. Trial $2019-\mathrm{C}$ list of treatments. On the date where an " $x$ " is present in the LL017 column, LL017 was added to the corresponding dosage of conventional fungicide (PPP). In the column PPP: $\mathrm{C}=$ Copper-based fungicide, $\mathrm{S}=$ Systemic fungicide, $\mathrm{S}-\mathrm{C}=$ fungicide both copper-based and with systemic actives.

\begin{tabular}{|c|c|c|c|c|c|c|c|c|}
\hline \multirow[t]{2}{*}{$\mathrm{T}$} & \multirow[t]{2}{*}{ Date } & \multirow[t]{2}{*}{ PPP } & \multicolumn{2}{|c|}{$\begin{array}{c}\text { Control } \\
\text { Strategy A }\end{array}$} & \multicolumn{2}{|c|}{$\begin{array}{c}\text { Strategy A + } \\
\text { LL017 }\end{array}$} & \multicolumn{2}{|c|}{$\begin{array}{c}\text { Positive } \\
\text { control }\end{array}$} \\
\hline & & & LL017 & PPP & LL017 & PPP & LL017 & PPP \\
\hline A & 13.05 & C & & $75 \%$ & & $75 \%$ & & $100 \%$ \\
\hline B & 20.05 & C & & $75 \%$ & & $75 \%$ & & $100 \%$ \\
\hline C & 28.05 & C & & $75 \%$ & & $75 \%$ & & $100 \%$ \\
\hline D & 04.06 & C & & $50 \%$ & $x$ & $50 \%$ & & $100 \%$ \\
\hline $\mathrm{E}$ & 11.06 & C & & $50 \%$ & $x$ & $50 \%$ & & $100 \%$ \\
\hline $\mathrm{F}$ & 18.06 & C & & $50 \%$ & $x$ & $50 \%$ & & $100 \%$ \\
\hline G & 24.06 & C & & $75 \%$ & & $75 \%$ & & $100 \%$ \\
\hline $\mathrm{H}$ & 05.07 & C & & $75 \%$ & & $75 \%$ & & $100 \%$ \\
\hline 1 & 12.07 & C & & $75 \%$ & & $75 \%$ & & $100 \%$ \\
\hline
\end{tabular}

Table 2. Trial $2019-\mathrm{V}$ list of treatments. On the date where an " $x$ " is present in the LL017 column, LL017 was added to the corresponding dosage of conventional fungicide (PPP). In the column PPP: $\mathrm{C}=$ Copper-based fungicide, $\mathrm{S}=$ Systemic fungicide, $\mathrm{S}-\mathrm{C}=$ fungicide both copper-based and with systemic actives.

\begin{tabular}{|c|c|c|c|c|c|c|c|c|c|c|c|c|}
\hline \multirow[t]{2}{*}{$\mathrm{T}$} & \multirow[t]{2}{*}{ Date } & \multirow[t]{2}{*}{ PPP } & \multicolumn{2}{|c|}{$\begin{array}{c}\text { Control } \\
\text { Strategy B }\end{array}$} & \multicolumn{2}{|c|}{$\begin{array}{c}\text { Strategy B + } \\
\text { LL017 }\end{array}$} & \multicolumn{2}{|c|}{$\begin{array}{c}\text { Control } \\
\text { Strategy C }\end{array}$} & \multicolumn{2}{|c|}{$\begin{array}{c}\text { Strategy C + } \\
\text { LL017 }\end{array}$} & \multicolumn{2}{|c|}{$\begin{array}{c}\text { Positive } \\
\text { control }\end{array}$} \\
\hline & & & LL017 & PPP & LL017 & PPP & LL017 & PPP & LL017 & PPP & LL017 & PPP \\
\hline A & 10.05 & C & & $70 \%$ & $x$ & $70 \%$ & & $0 \%$ & $x$ & $0 \%$ & & $100 \%$ \\
\hline B & 17.05 & C & & $70 \%$ & $x$ & $70 \%$ & & $0 \%$ & $x$ & $0 \%$ & & $100 \%$ \\
\hline C & 22.05 & $S$ & & $70 \%$ & $x$ & $70 \%$ & & $100 \%$ & & $100 \%$ & & $100 \%$ \\
\hline D & 29.05 & $S-C$ & & $70 \%$ & $x$ & $70 \%$ & & $100 \%$ & & $100 \%$ & & $100 \%$ \\
\hline$E$ & 07.06 & $S-C$ & & $70 \%$ & $x$ & $70 \%$ & & $0 \%$ & $x$ & $0 \%$ & & $100 \%$ \\
\hline $\mathrm{F}$ & 11.06 & S-C & & $70 \%$ & $x$ & $70 \%$ & & $100 \%$ & & $100 \%$ & & $100 \%$ \\
\hline G & 18.06 & $S-C$ & & $70 \%$ & $x$ & $70 \%$ & & $100 \%$ & & $100 \%$ & & $100 \%$ \\
\hline $\mathrm{H}$ & 25.06 & C & & $70 \%$ & $x$ & $70 \%$ & & $0 \%$ & $x$ & $0 \%$ & & $100 \%$ \\
\hline 1 & 02.07 & C & & $70 \%$ & $x$ & $70 \%$ & & $0 \%$ & $x$ & $0 \%$ & & $100 \%$ \\
\hline $\mathrm{J}$ & 08.07 & $S-C$ & & $70 \%$ & $x$ & $70 \%$ & & $100 \%$ & & $100 \%$ & & $100 \%$ \\
\hline $\mathrm{K}$ & 17.07 & C & & $70 \%$ & $x$ & $70 \%$ & & $0 \%$ & $x$ & $0 \%$ & & $100 \%$ \\
\hline L & 24.07 & C & & $70 \%$ & $x$ & $70 \%$ & & $0 \%$ & $x$ & $0 \%$ & & $100 \%$ \\
\hline
\end{tabular}

Table 3. Trial $2020-\mathrm{V}$ list of treatments. On the date where an " $x$ " is present in the LL017 column, LL017 was added to the corresponding dosage of conventional fungicide (PPP). In the column PPP: $\mathrm{C}=$ Copper-based fungicide, $\mathrm{S}=$ Systemic fungicide, $\mathrm{S}-\mathrm{C}=$ fungicide both copper-based and with systemic actives.

\begin{tabular}{|c|c|c|c|c|c|c|c|c|c|c|c|c|}
\hline \multirow[t]{2}{*}{$\mathrm{T}$} & \multirow[t]{2}{*}{ Date } & \multirow[t]{2}{*}{ PPP } & \multicolumn{2}{|c|}{$\begin{array}{c}\text { Control } \\
\text { Strategy B }\end{array}$} & \multicolumn{2}{|c|}{$\begin{array}{c}\text { Strategy B + } \\
\text { LL017 }\end{array}$} & \multicolumn{2}{|c|}{$\begin{array}{c}\text { Control } \\
\text { Strategy D }\end{array}$} & \multicolumn{2}{|c|}{$\begin{array}{c}\text { Strategy D + } \\
\text { LL017 }\end{array}$} & \multicolumn{2}{|c|}{$\begin{array}{l}\text { Positive } \\
\text { control }\end{array}$} \\
\hline & & & LL017 & PPP & LL017 & PPP & LL017 & PPP & LL017 & PPP & LL017 & PPP \\
\hline A & 09.05 & C & & $70 \%$ & $x$ & $70 \%$ & & $60 \%$ & $x$ & $60 \%$ & & $100 \%$ \\
\hline$B$ & 18.05 & $S-C$ & & $70 \%$ & $x$ & $70 \%$ & & $60 \%$ & $x$ & $60 \%$ & & $100 \%$ \\
\hline C & 26.05 & $S$ & & $70 \%$ & $x$ & $70 \%$ & & $85 \%$ & & $85 \%$ & & $100 \%$ \\
\hline$D$ & 03.06 & $S-C$ & & $70 \%$ & $x$ & $70 \%$ & & $85 \%$ & & $85 \%$ & & $100 \%$ \\
\hline$E$ & 12.06 & C & & $70 \%$ & $x$ & $70 \%$ & & $60 \%$ & $x$ & $60 \%$ & & $100 \%$ \\
\hline $\mathrm{F}$ & 18.06 & $S$ & & $70 \%$ & $x$ & $70 \%$ & & $60 \%$ & $x$ & $60 \%$ & & $100 \%$ \\
\hline G & 26.06 & C & & $70 \%$ & $x$ & $70 \%$ & & $85 \%$ & & $85 \%$ & & $100 \%$ \\
\hline $\mathrm{H}$ & 06.07 & $S-C$ & & $70 \%$ & $x$ & $70 \%$ & & $60 \%$ & $x$ & $60 \%$ & & $100 \%$ \\
\hline I & 15.07 & C & & $70 \%$ & $x$ & $70 \%$ & & $85 \%$ & & $85 \%$ & & $100 \%$ \\
\hline J & 23.07 & C & & $70 \%$ & $x$ & $70 \%$ & & $60 \%$ & $x$ & $60 \%$ & & $100 \%$ \\
\hline
\end{tabular}


The commercial products were used according to the manufacturer's information, using always the minimum dosage.

\section{Results and Discussion}

\subsection{Efficacy of Strategy A (StA): trial 2019 - C}

\section{$3.1 .1 \%$ of efficacy in leaves}

The first disease symptoms on leaves appeared on the $18^{\text {th }}$ of June. In fact, the major incidence on the leaves was found on the CTR - plants, while the best one was generally the CTR + .

The use of less PPP decreased the efficacy of the treatments, with higher impact when LL017 was not added to the treatment (CTR StA). In fact, the use of LL017 significantly increased the efficacy of the treatments both on incidence and on severity (StA), compared to CTR StA (Table 4).

Table 4. Trial 2019 - C: statistical analysis of the \% of efficacy of the different treatments on the incidence (upper panel) and severity (lower panel) of downy mildew on the leaves.

\begin{tabular}{|c|c|c|c|}
\hline Entry & 18.06 & 05.07 & 19.07 \\
\hline CTR StA & \begin{tabular}{l|l}
60,5 & $\mathrm{a}$ \\
\end{tabular} & \begin{tabular}{l|l}
19,1 & $\mathrm{a}$ \\
\end{tabular} & \begin{tabular}{l|l}
5,1 & $\mathrm{a}$ \\
\end{tabular} \\
\hline StA & \begin{tabular}{l|l}
64,8 & $\mathrm{a}$ \\
\end{tabular} & \begin{tabular}{l|l|}
36,1 & $b$ \\
\end{tabular} & \begin{tabular}{ll|l}
31,8 & $\mathrm{~b}$ \\
\end{tabular} \\
\hline CTR + & \begin{tabular}{l|l|}
83,6 & $\mathrm{~b}$ \\
\end{tabular} & \begin{tabular}{l|l}
60,5 & $\mathrm{c}$ \\
\end{tabular} & \begin{tabular}{l|l|l}
38,2 & $\mathrm{c}$ \\
\end{tabular} \\
\hline Entry & 18.06 & 05.07 & 19.07 \\
\hline CTR StA & \begin{tabular}{l|l}
89,5 & $\mathrm{a}$ \\
\end{tabular} & \begin{tabular}{l|l}
56,5 & $\mathrm{a}$ \\
\end{tabular} & \begin{tabular}{l|l}
59,3 & $\mathrm{a}$ \\
\end{tabular} \\
\hline StA & \begin{tabular}{l|l|}
92,9 & $\mathrm{ab}$ \\
\end{tabular} & \begin{tabular}{l|l|}
69,5 & $\mathrm{ab}$ \\
\end{tabular} & $68,7 \mathrm{~b}$ \\
\hline CTR + & $95,9 \mid \mathrm{b}$ & $79,5 \mathrm{~b}$ & \begin{tabular}{l|l}
81,3 & $\mathrm{c}$ \\
\end{tabular} \\
\hline
\end{tabular}

\subsection{2 \% of efficacy in bunches}

On the same dates as in leaves, the assessment on the disease was performed also on bunches.

The disease pressure was very high, with $100 \%$ and $51 \%$ of bunches covered by the fungi for more than the $60 \%$ and less than $10 \%$ of the surface of CTR - and CTR + respectively in one month (Fig. 1).

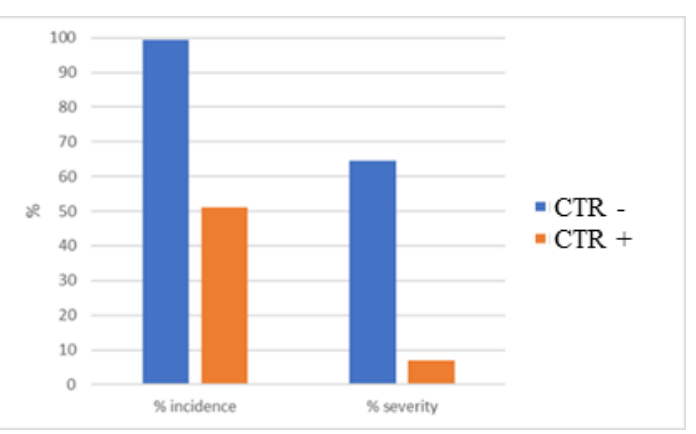

Fig. 1. Trial $2019-$ C: $\%$ of incidence and severity of downy mildew on the bunches of CTR - and CTR + .

Overall, the best efficacy against the disease was found in CTR + both in the incidence and the severity.
All the treated entries showed an efficacy close to CTR + (in particular in the first assessments), but then started to decrease. Also on bunches, the use of LL017 significantly increased the efficacy of the treatment both on incidence and on severity, performing statistically better than the respective control at the same level of PPP (Table 5).

Table 5. Trial 2019 - C: statistical analysis of the \% of efficacy of the different treatments on the incidence (upper panel) and severity (lower panel) of downy mildew on the bunches.

\begin{tabular}{|c|c|c|c|}
\hline En try & 18.06 & 05.07 & 19.07 \\
\hline CTR StA & $98,1 \mid \mathrm{a}$ & \begin{tabular}{l|l}
31,5 & $\mathrm{a}$ \\
\end{tabular} & \begin{tabular}{l|l}
16,6 & $\mathrm{a}$ \\
\end{tabular} \\
\hline StA & \begin{tabular}{l|l}
98,1 & $\mathrm{a}$ \\
\end{tabular} & \begin{tabular}{l|l}
47,2 & $b$ \\
\end{tabular} & $27,4 \mid \mathrm{b}$ \\
\hline CTR + & \begin{tabular}{l|l}
100 & $\mathrm{a}$ \\
\end{tabular} & \begin{tabular}{l|l|l}
70,1 & $\mathrm{c}$ \\
\end{tabular} & \begin{tabular}{l|l|l}
48,7 & $\mathrm{c}$ \\
\end{tabular} \\
\hline Entry & 18.06 & 05.07 & 19.07 \\
\hline CTR StA & \begin{tabular}{l|l}
99,8 & $\mathrm{a}$ \\
\end{tabular} & \begin{tabular}{l|l}
81,9 & $\mathrm{a}$ \\
\end{tabular} & \begin{tabular}{l|l}
73,3 & $\mathrm{a}$ \\
\end{tabular} \\
\hline StA & \begin{tabular}{l|l}
99,8 & $\mathrm{a}$
\end{tabular} & \begin{tabular}{l|l|}
86 & $\mathrm{a}$
\end{tabular} & $\begin{array}{l}83,7 \\
b\end{array}$ \\
\hline CTR + & \begin{tabular}{c|c}
100 & $a$
\end{tabular} & \begin{tabular}{ll|l}
91,3 & $b$
\end{tabular} & $89 \mathrm{c}$ \\
\hline
\end{tabular}

\subsection{Efficacy of Strategy B (StB) and C (StC): trial $2019-V$}

There were no symptoms in the leaves, therefore, only bunches were assessed.

\subsection{1\% of efficacy in bunches}

The first disease symptoms on leaves appeared on the $18^{\text {th }}$ of June. At the last assessment, the incidence/ severity of downy mildew was $45 \% / 10 \%$ and $21 \% / 2 \%$ for the CTR - and CTR + respectively (Fig. 2).

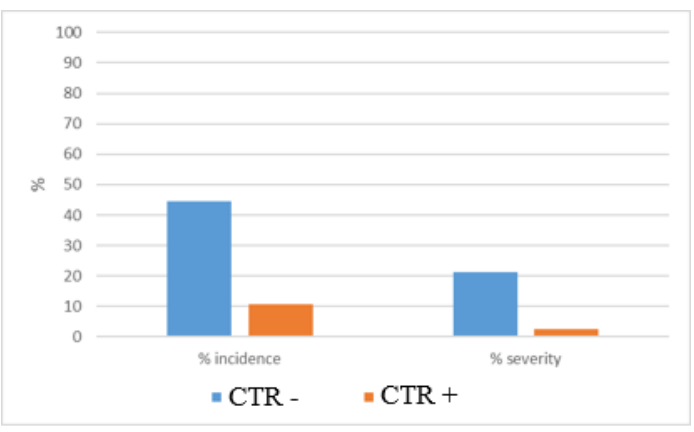

Fig. 2. Trial $2019-$ V: \% of incidence and severity of downy mildew on the bunches of CTR - and CTR + .

Overall, the best efficacy against the disease was found in CTR + both in the incidence and the severity (efficacy close to 90\%). All the treated entries showed an efficacy close to the CTR + (in particular at the beginning of the assessments), but then started to decrease (in particular in the incidence). The worst performance was achieved by CTR $\mathrm{StC}$, which is the only entry statistically significant different from the CTR +, while the use of LL017 in this strategy, as a trend, increased the efficacy on both incidence and severity of the treatment. Also in StB, as a trend, 
treatment with LL017 increased the efficacy on the severity compared to the CTR StB (Table 6).

Table 6. Trial $2019-$ V: statistical analysis of the $\%$ of efficacy of the different treatments on the incidence (upper panel) and severity (lower panel) of downy mildew on the bunches.

\begin{tabular}{|c|c|c|c|c|c|}
\hline Entry & 18.06 & 25.06 & 02.07 & 17.07 & 07.08 \\
\hline CTR + & \begin{tabular}{l|l}
94,3 & $\mathrm{a}$ \\
\end{tabular} & $\begin{array}{l}87,5 \mid \mathrm{a} \\
\end{array}$ & \begin{tabular}{l|l}
88,2 & $\mathrm{a}$ \\
\end{tabular} & $87,7 \mid \mathrm{a}$ & $85,7 \mid \mathrm{c}$ \\
\hline CTR StB & $\begin{array}{l}93,2 \\
\end{array}$ & $\begin{array}{ll}95,3 & \mathrm{a} \\
\end{array}$ & $91,3 \mathrm{a}$ & $79,1] \mathrm{a}$ & $71,4 \mathrm{bc}$ \\
\hline StB & \begin{tabular}{l|l}
90,6 & $\mathrm{a}$ \\
\end{tabular} & $\begin{array}{l}90,8 \\
\mathrm{a}\end{array}$ & \begin{tabular}{l|l}
86,3 & $\mathrm{a}$ \\
\end{tabular} & \begin{tabular}{ll|l}
67,5 & $\mathrm{a}$ \\
\end{tabular} & $81,5 \mid b c$ \\
\hline CTR StC & \begin{tabular}{l|l|l}
89,6 & $\mathrm{a}$ \\
\end{tabular} & \begin{tabular}{ll|l}
88,0 & $a$ \\
\end{tabular} & $79,1 \mathrm{a}$ & \begin{tabular}{|l|l}
57,7 & $\mathrm{a}$ \\
\end{tabular} & \begin{tabular}{l|l|}
53,5 & $\mathrm{a}$ \\
\end{tabular} \\
\hline $\mathrm{StC}$ & \begin{tabular}{l|l|l}
93,7 & $\mathrm{a}$ \\
\end{tabular} & \begin{tabular}{l|l|l}
85,1 & $\mathrm{a}$ \\
\end{tabular} & \begin{tabular}{l|l|l}
88,4 & $\mathrm{a}$ \\
\end{tabular} & \begin{tabular}{l|l|}
74,6 & $\mathrm{a}$ \\
\end{tabular} & \begin{tabular}{l|l|}
67,2 & $\mathrm{ab}$ \\
\end{tabular} \\
\hline \begin{tabular}{|l} 
Entry \\
\end{tabular} & 18.06 & 25.06 & 02.07 & 17.07 & 07.08 \\
\hline CTR + & \begin{tabular}{l|l}
93,9 & $\mathrm{a}$ \\
\end{tabular} & \begin{tabular}{l|l|}
90,0 & $\mathrm{ab}$ \\
\end{tabular} & \begin{tabular}{l|l|l}
87,8 & $\mathrm{a}$ \\
\end{tabular} & \begin{tabular}{l|l}
87,9 & a \\
\end{tabular} & \begin{tabular}{l|l}
92,8 & $\mathrm{~b}$ \\
\end{tabular} \\
\hline CTR StB & \begin{tabular}{l|l}
93,2 & $\mathrm{a}$ \\
\end{tabular} & \begin{tabular}{l|l}
98,0 & $\mathrm{~b}$ \\
\end{tabular} & \begin{tabular}{l|l}
92,9 & $\mathrm{a}$ \\
\end{tabular} & \begin{tabular}{l|l}
89,9 & a \\
\end{tabular} & $\begin{array}{lll}88,0 & a b \\
\end{array}$ \\
\hline StB & \begin{tabular}{l|l}
90,6 & $\mathrm{a}$ \\
\end{tabular} & \begin{tabular}{l|l}
96,3 & $\mathrm{~b}$ \\
\end{tabular} & \begin{tabular}{l|l}
91,6 & $\mathrm{a}$ \\
\end{tabular} & \begin{tabular}{l|l}
86,3 & $\mathrm{a}$ \\
\end{tabular} & $\begin{array}{l}93,7 \\
\end{array}$ \\
\hline CTR StC & $\begin{array}{l}89,6 \\
\end{array}$ & \begin{tabular}{l|l|}
91,7 & $\mathrm{ab}$ \\
\end{tabular} & \begin{tabular}{ll|l}
82,1 & $\mathrm{a}$ \\
\end{tabular} & 81,4 a & $82,8 \mathrm{a}$ \\
\hline StC & $93,4 \mid \mathrm{a}$ & 84,1 a & $92,7 \mid \mathrm{a}$ & $88,3] \mathrm{a}$ & $87,3 \mathrm{ab}$ \\
\hline
\end{tabular}

\subsubsection{Yield}

At the end of the trial the yield was assessed. As expected, the CTR - was the worst among all the entries, while the best one was the StB (Table 7). The only statistically significant difference, but for the difference with CTR -, was found between CTR StC and StB. No statistically significant differences between the strategies + LL017 and their respective controls could be found. However, as a trend, addition of LL017 increased production by almost $6 \%$ in StB and more than $9 \%$ in StC. In general, all the entries showed more than $40 \%$ more production compared to CTR -, with CTR + showing $+68 \%, \mathrm{StB}+87 \%$ and $\mathrm{StC}+58 \%$. Comparing the treatments to CTR +, we can see StB showed $+11 \%$ yield while there was a slight decrease for $\operatorname{StC}(-6 \%)$.

Table 7. Trial 2019 - V: statistical analysis of the yield,

\begin{tabular}{|l|c|c|}
\hline Entry & \multicolumn{2}{|c|}{ Ton/ha } \\
\hline CTR + & 21,2 & bc \\
\hline CTR StB & 22,2 & bc \\
\hline StB & 23,5 & c \\
\hline CTR StC & 18,2 & b \\
\hline StC & 19,9 & bc \\
\hline CTR - & 12,6 & a \\
\hline
\end{tabular}

\subsection{Efficacy of Strategy B (StB) and D (StD): trial 2020 - V}

There were no symptoms in the leaves, therefore, only bunches were assessed.

\subsection{1 \% of efficacy in bunches}

The first disease symptoms on leaves appeared on the $7^{\text {th }}$ of July. At the last assessment, the incidence/severity of downy mildew was $50 \% / 19 \%$ and $13 \% / 2 \%$ for the CTR - and CTR + respectively (Fig. 3).

The severity and incidence of the disease were assessed three time on the bunches.
Overall, the best efficacy against the disease was found in CTR + both in the incidence and the severity, with an efficacy close to $80 \%$ and $90 \%$ respectively. The worst performance was achieved by CTR StB and CTR StD. The use of LL017 in both these strategies (as a trend) increased the efficacy of the treatment (Table 8).

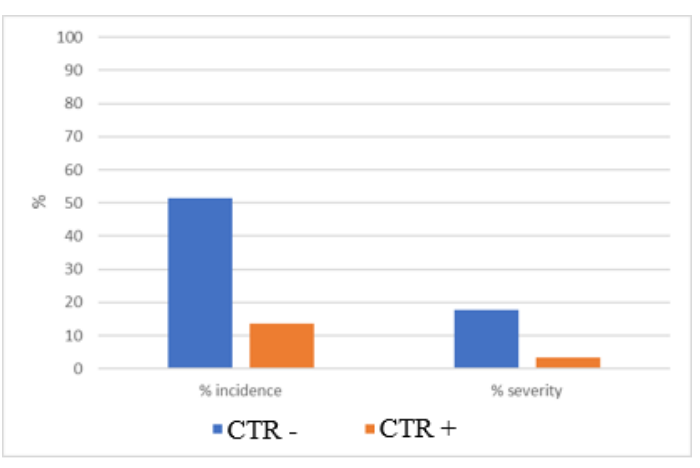

Fig. 3. Trial $2020-$ V: $\%$ of incidence and severity of downy mildew on the bunches of CTR - and CTR + .

Table 8. Trial $2020-\mathrm{V}$ : statistical analysis of the $\%$ of efficacy of the different treatments on the incidence (upper panel) and severity (lower panel) of downy mildew on the bunches.

\begin{tabular}{|c|c|c|c|}
\hline En try & 07.07 & 16.07 & 28.07 \\
\hline CTR + & \begin{tabular}{l|l}
80,6 & $\mathrm{a}$ \\
\end{tabular} & $76,8 \mathrm{a}$ & $75,4 \mathrm{a}$ \\
\hline CTR StB & \begin{tabular}{l|l}
39,9 & $\mathrm{a}$ \\
\end{tabular} & 64,3 & $47,0 \mathrm{a}$ \\
\hline StB & \begin{tabular}{l|l}
69,3 & $\mathrm{a}$ \\
\end{tabular} & 67,9 & \begin{tabular}{l|l|}
66,7 & $a$
\end{tabular} \\
\hline CTR StD & \begin{tabular}{l|l}
48,3 & $\mathrm{a}$ \\
\end{tabular} & 50,7 a & 44,6 a \\
\hline StD & \begin{tabular}{l|l}
66,6 & $\mathrm{a}$ \\
\end{tabular} & \begin{tabular}{l|l}
62,3 & $\mathrm{a}$ \\
\end{tabular} & \begin{tabular}{l|l}
61,5 & $a$ \\
\end{tabular} \\
\hline Entry & 07.07 & 16.07 & 28.07 \\
\hline $\mathrm{CTR}+$ & \begin{tabular}{l|l}
95,8 & $\mathrm{a}$ \\
\end{tabular} & 89,2 & \begin{tabular}{l|l|l}
83,7 & a \\
\end{tabular} \\
\hline CTR StB & \begin{tabular}{l|l}
65,0 & $\mathrm{a}$ \\
\end{tabular} & 77,6 a & $65,1 \mathrm{a}$ \\
\hline StB & \begin{tabular}{l|l}
67,6 & $\mathrm{a}$ \\
\end{tabular} & $72,4 \mathrm{a}$ & $82,5 \mathrm{a}$ \\
\hline CTR StD & \begin{tabular}{|l|l|}
63,2 & $\mathrm{a}$ \\
\end{tabular} & 64,6 & $60,9 \mathrm{a}$ \\
\hline StD & \begin{tabular}{|l|l|}
72,8 & $\mathrm{a}$ \\
\end{tabular} & 74,9 & 76,0 a \\
\hline
\end{tabular}

\subsubsection{Yield}

As expected, CTR - was the worst among all the entries, while the best one was StD (Table 9). The controls of both strategies were not statistically significant different from both CTR - and CTR +, although higher than the former in trend. Entries with LL017 in both strategies and CTR + had instead statistically significant higher production compared to CTR -. In general, the entries showed more than $48 \%$ increase in production compared to CTR -, with CTR + showing $+74 \%, \mathrm{StB}+84 \%$ and $\mathrm{StD}+93 \%$. Comparing LL017 effect to the respective controls with the same amount of PPP, there was an increase in production by almost $20 \%$ in StB and $11 \%$ in StD. 
Table 9. Trial 2019 - V: statistical analysis of the yield,

\begin{tabular}{|l|r|c|}
\hline Entry & \multicolumn{2}{|c|}{ Ton/ha } \\
\hline CTR + & 11,2 & $\mathrm{~b}$ \\
\hline CTR StB & 9,9 & $\mathrm{ab}$ \\
\hline StB & 11,9 & $\mathrm{~b}$ \\
\hline CTR StD & 9,5 & $\mathrm{ab}$ \\
\hline StD & 12,4 & $\mathrm{~b}$ \\
\hline CTR - & 6,4 & $\mathrm{a}$ \\
\hline
\end{tabular}

\section{Conclusion}

In the reported trials, 4 strategies aimed to decrease the utilization of PPP against downy mildew were conducted, using a plant extract added to the PPP at a reduced dosage. Among the different strategies, Strategy $\mathrm{C}$ resulted to be the least effective, although the addition of LL017, as a trend, decreased the disease incidence and severity compared to the control. Strategy A gave the clearest results, but the addition of LL017 was not sufficient to reach the levels of protection of the full dosage of fungicide. Strategies B and D gave the best results, both in terms of increased tolerance to the disease and yield. In fact, it is interesting to notice that, although in some cases the efficacy of the reduced dosage of PPP + LL017 was slightly lower than the positive control, the yield was always higher, indicating a possible biostimulant effect of LL017 on the plants.

In conclusion, the use of LL017 fortified plants, making them stronger against the disease, as seen both by the lower $\%$ of incidence and severity and the higher yield.

This work was funded by the EU Project LIFE18 ENV/NL/000043 Plants for Plants. A special acknowledgement to Sumitomo Chemical Italia for kindly hosting the 2019 - C trial.

\section{References}

1. M. Van Helden, Kreiter S. ed. Ravageurs de la vigne. Féret, 2008: 321-335 (2008)

2. A. Aziz, P. Trotel-Aziz, L. Dhuicq, P. Jeandet, M. Couderchet, G. Vernt, Phytopathology, 96, 11881194 (2006)

3. H.Y. Sun, H.C. Wang, G. Stammler, J.X. Ma, J. M. Liu, M.G. Zhou, J. Phytopathol, 158, 450-452 (2010)

4. Q.Y. Bi, Z.Q. Ma, X.Y. Han, X.F. Zhang, W.Q. Wang, J.J. Zhao, Acta Phytopathol. Sin., 44, 302308 (2014)

5. X.N. Wang, M. Wang, F.F. Kong, Z.Y. Wang, H. Zhang, Plant Prot., 44, 139-142 (2018)

6. C.L. Matasci, D. Gobbin, H.J. Scharer, L. Tamm, C. Gessler, Eur. J. Plant Pathol., 120, 79-83 (2008)

7. D. Sande, J. Mullen, M. Wetzstein, J. Houston, Int. J. Environ. Res. Public Health, 12, 4649-4661 (2011)

8. W.F. Peng, K.T. Li, Y.J. Zeng: Advances in the researches into microbiological control of rice diseases. Acta Agric. Univ. Jiangxi., 37, 625-631 (2015)

9. S. Kagale, T. Marimuthu, B. Thayumanavan, R. Nandakumar, R. Samiyappan, Physiol. Mol. Plant Pathol., 65,91-100 (2005)

10. P. Achimu and A. Schlösser, Medical Faculty Landbouw University Gent 57, 423-431 (1992)

11. S. Schnee, E. F. Queiroz, F. Voinesco, L. Marcourt, P. H. Dubuis, J. L. Wolfender, K. Gindro, J. Agric. Food Chem. 61, 5459-5467 (2013)

12. Y. Cohen, W. Wang, B.-H. Ben-Daniel, Y. BenDaniel, Phytopathology 96, 417-424 (2006)

13. A. Jamiołkowska, Agronomy, 10, 173 (2020)

14. W. Abbott, J. Econ. Entomol., 18, 265-267 (1925) 